http://jmscr.igmpublication.org/home/

ISSN (e)-2347-176x ISSN (p) 2455-0450

crossref DOI: https://dx.doi.org/10.18535/jmscr/v7i12.34

Journal Of Medical Science And Clinical Research

\title{
A Clinico-Pathological Analysis of 30 Cases of Chronic Recurrent Tonsillitis
}

\author{
Authors \\ Apurva Sharma, Kalpana Rajiv Kumar, Jubina Puthen Purayil, \\ Neelikattu Aathira Tess Thomas \\ Department of Otorhinolaryngology, MGM Hospital Navi Mumbai \\ *Corresponding Author \\ Kalpana Rajiv Kumar
}

\begin{abstract}
Chronic tonsillitis is a common inflammatory disease of childhood. Chronic recurrent tonsillitis is common indication of tonsillectomy. Tonsillectomy is one of the most common otolaryngologic surgical procedures. There is still an ongoing debate as to whether or not histopathological examination should be performed in chronic recurrent Tonsillitis after tonsillectomy.
\end{abstract}

Objective: The aim of the study is to evaluate the correlations between clinical findings and histopathological findings in patients with chronic recurrent tonsillitis.

Material and Methods: A retrospective study was carried out in 30 patients with chronic recurrent tonsillitis who had undergone tonsillectomy from November 2017 to June 2019 in MGM hospital. The results were assessed in terms of various histological changes in removed tonsils.

Results: The patient's ages ranged between 4 years to 55 years. A total of 30 cases were included in the present study. Of all the patients who underwent tonsillectomy, two were detected with malignancy.

Conclusion: A routine histopathologic examination is necessary for every cases of tonsillectomy, especially in adult population.

Keywords: Tonsillectomy, Histopathology, Malignancy.

\section{Introduction}

Palatine tonsils are part of Waldeyer's lymphatic ring, responsible for the first line of defence against pathogen. It is located at the entrance of the air and digestive tract. ${ }^{1}$ A palatine tonsil lies in the tonsillar fossa and is lined by stratified squamous epithelium and crypts are covered by non-keratinizing stratified "transitional type" epithelium with a discontinuous basement membrane and intraepithelial lymphoid cells. ${ }^{2}$

Tonsillitis occurs if the activity and proliferation of pathogens in the tonsillar lymphoid tissue exceed the protective potency of activated lymphoid and immunoglobulin producing cells. ${ }^{3}$
In this situation, especially in chronic or recurrent cases, tonsillectomy is a common therapeutic approach. ${ }^{4}$ It has to be taken into consideration that large palatine tonsils alone are not necessarily an indication for tonsillectomy, because tonsils are normally much larger in children than in adults and physiologically in volute during adolescence. $^{5,6}$ The diagnosis of the chronic tonsillitis is usually based on clinical history. Seven or more episodes in the preceding year or five or more episodes in each of the two preceding years be accepted as clinical criterion of the chronic tonsillitis and as an indication for tonsillectomy. ${ }^{7}$ 
Tonsillectomy is an operation performed for diverse indications among which, recurrent episodes of chronic tonsillitis is the commonest. Other indications include unilateral tonsillar enlargement, a first attack of quinsy (peritonsillar abscess), sleep apnea syndrome and during surgical treatment of glossopharyngeal neuralgia or during the excision of the elongated styloid process in Eagle's syndrome. Tonsillectomy is one of the most performed surgeries in ENT practice, particularly in children, due to the intense activity and large amounts of lymphoid tissue existing in these periods of their lives.

There is no clear consensus on whether post tonsillectomy specimens should be examined routinely for histopathology. Considering the expenditure and labour power in the laboratory, some authors suggested that, histopathological analysis of tonsil is needed when clinical suspicion of malignancy is high. ${ }^{8}$ Increasing malignancy rates in tonsils especially in adults reveal the necessity of routine histopathological examination. The incidence of malignant pathologies after tonsillectomy in adults ranges from $2 \%$ to $10 \%$. 9,10

In this study, we aimed comparing clinical findings and routine histopathological examination in patients of chronic recurrent tonsillitis who underwent tonsillectomy in our hospital.

\section{Material and Methods}

This study was approved by the clinical research ethics committee of MGM hospital Navi Mumbai. Retrospective study of 30 cases of chronic recurrent tonsillitis who had undergone tonsillectomy between November 2017 and June 2019 were retrieved from the files of MGM hospital. Materials within the files of each patient were supplemented by detailed history clinical examination, operative notes and intra-operative findings. In routine practice, samples obtained after tonsillectomy were macroscopically and histopathologically evaluated by the pathologists of our hospital. Follow up data included information regarding histopathological evidence of specific diseases, development of specific disease, and the current status of the patient. The confidentiality of the patients was maintained throughout the study. Exclusion criteria were patients of acute tonsillitis, suspected malignancy of tonsil and unilateral enlargement of tonsil.

The tonsils removed were identified as left and right and fixed in $10 \%$ formaldehyde. After surgical specimen fixation we did macroscopic description (weight, measurements, and features). The material was subsequently processed, embedded in paraffin and stained with hematoxylin- eosin (HE) technique for general specimen evaluation; Masson trichrome and reticle to assess fibrosis and the support reticular framework, respectively. The slide were analysed by a pathologists, and evaluated the slides using criteria used by Lope et al. ${ }^{11}$ Lymph follicles, germinal centres, fibrosis and necrosis. Depending on the severity of inflammation four histological types of chronic recurrent tonsillitis were established: (1) pure hyperplasia (2) chronic inflammation (3) chronic inflammation with hyperplasia (4) chronic inflammation with scarring and fibrosis.

\section{Results}

A total of 30 patients of chronic recurrent tonsillitis and tonsils specimens were examined. Patients aged 1- 17 years were grouped as paediatric and patients aged 18 years or older were grouped as adult. There were 16 paediatric patients and 14 adult patients included in the study. The mean ages of the children and adults were (1-17) and (18-55) years respectively. Of all the patients, 11 were males and 19 were females. Significant pathological findings were observed in all patients. Out of 30 specimens 27 were reported as reactive lymphoid hyperplasia, with chronic inflammation, 1 specimen showed granulomatous inflammation, and malignancy was detected in 2 cases, these patients were in the adult patient group. No malignancy was detected in the paediatric patient group. Chronic tonsillitis 
histologically manifested as follicular hyperplasia and chronic inflammation is a common pathological condition which we got in most of the patients.

\section{Age Distribution}

Table1 Age Distribution

\begin{tabular}{|c|c|}
\hline Age ( years) & No of patients \\
\hline $1-17$ & 16 \\
\hline $18-55$ & 14 \\
\hline
\end{tabular}

\section{Age distribution of patients}

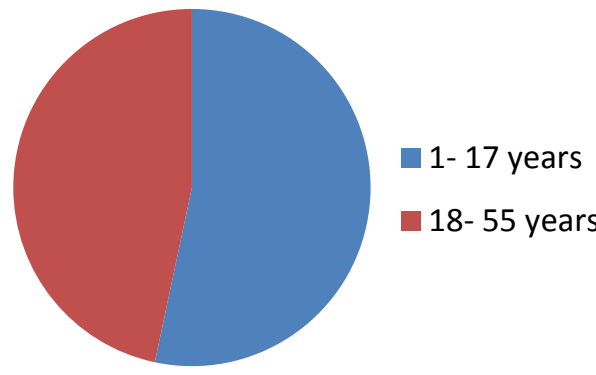

Graph 1 Showing Distribution of Age Group Affected By Chronic Recurrent Tonsillitis

\section{Gender Wise Distribution}

Table 2 Gender Wise Distribution

\begin{tabular}{|l|c|}
\hline Gender & No of patients \\
\hline Male & 11 \\
\hline Female & 19 \\
\hline Total & 30 \\
\hline
\end{tabular}

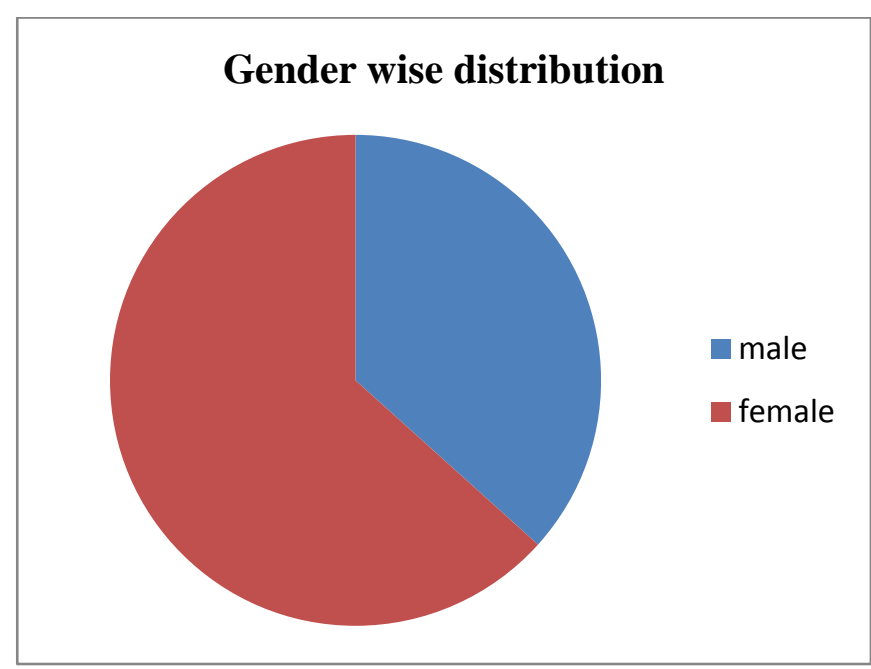

Graph 2 Showing Gender Wise Distribution, Female Are Affected More Than Male Population
Histopathological Findings of Tonsil Specimen in 30 Patients of Chronic Recurrent Tonsillitis-

Table 3: Histopathological Findings of Tonsil Specimen in 30 Patients of Chronic Recurrent Tonsillitis

\begin{tabular}{|l|c|c|c|}
\hline Sr no & Pathological findings & $\begin{array}{c}\text { No.of } \\
\text { patients }\end{array}$ & $\begin{array}{c}\text { Percentage } \\
(\mathbf{\%})\end{array}$ \\
\hline $\mathbf{1}$ & $\begin{array}{c}\text { Chronic inflammation } \\
\text { with lymphoid } \\
\text { hyperplasia }\end{array}$ & 27 & $90 \%$ \\
\hline $\mathbf{2}$ & Granulomatous disease & 1 & $3.33 \%$ \\
\hline $\mathbf{3}$ & Malignancy & 2 & $6.66 \%$ \\
\hline
\end{tabular}

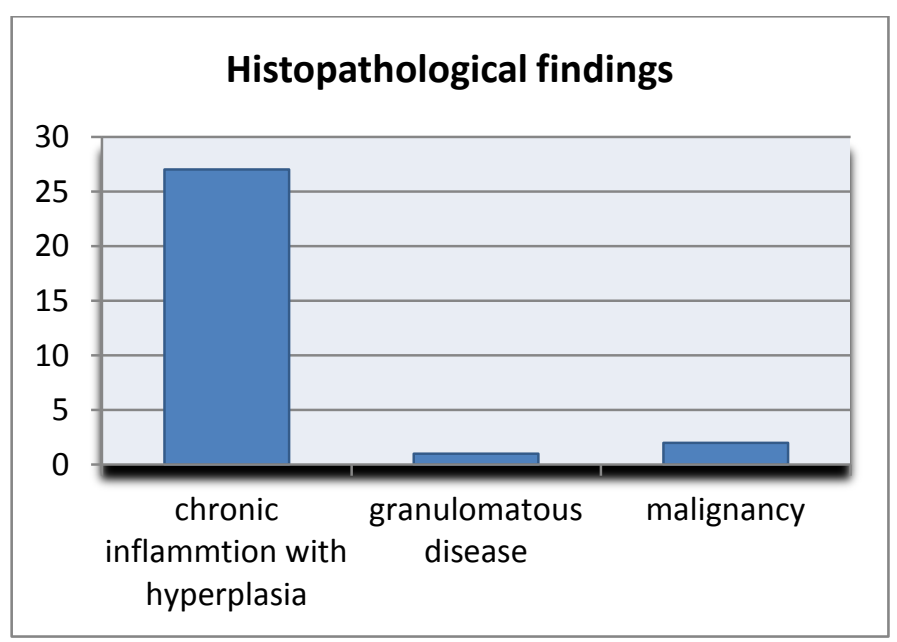

Graph 3 Showing Histopathological Findings of Tonsil Specimen in Patient with Chronic Recurrent Tonsillitis

Patient with granulomatous inflammation of tonsil is rare, which we got in 1 sample. Macroscopic appearance of the tonsil was yellow white and crypts were enlarged, and microscopically it showed scattered large granulomas, with central necrosis. The ziehl- Neelsen stain for acid fast bacilli was positive for this patient, and she developed culture- confirmed tuberculosis (Mycobacterium tuberculosis) after the initial evaluation of the her tonsillectomy specimen. The granulomatous inflammation of tonsil was secondary to a systemic disease. A patient was clinically diagnosed with pulmonary disease soon after the and was given systemic treatment. Patient showed no evidence of disease at last follow up. Malignancy was detected in 2 patients. Of these 2 patients, one had mucoepidermoid carcinoma of palatine tonsil, and the other had invasive well differentiated squamous cell carcinoma. The first 
patient was 45- year- old woman who had styloid process enlargement (eagles syndrome). She had undergone tonsillectomy and intra-operatively styloid process was not palpable. Due to intraoperative suspicion of finding, the histopathological result was correlated with clinical findings. The other patient was a 60 -yearold man who had tonsillar asymmetry on physical examination and operated due to chronic recurrent tonsillitis. Malignancy was not suspected in both the patients. Immunohistochemical evaluation in addition to routine examination was performed in both patients.

\section{Discussion}

The diagnosis of chronic tonsillitis is usually based on clinical history and throat related symptoms. However, there are very few studies which analysed correlations between clinical symptoms and histological findings of chronic recurrent tonsillitis. Ripplinger et al. in 2007 did not find a statistically significant correlation between tonsillitis and histological type of chronic tonsillitis; although chronic inflammation with tonsillar hyperplasia was the most common histological findings (42\%) in the group of investigated preschool children ${ }^{12}$.

Although histopathological examination is generally performed after tonsillectomy, there is still a debate about whether histopathological examination is necessary or it is required in which cases. In the study by Strong et al. ${ }^{13}$, it was found that $67 \%$ otolaryngologists send adult tonsillectomy specimens to the pathology laboratories, and that $38 \%$ send paediatric tonsillectomy specimens to the pathology laboratories. They have emphasized that paediatric patients should undergo histopathological examination especially in clinical situations, such as tonsillar asymmetry, mucosal changes, night fever, and cervical lymphadenopathy, and that specimens should be sent to the pathological laboratory in adult. In the study performed by Younis et al. ${ }^{9}$ while no malignancy was detected in 2099 paediatric tonsillectomy specimens, malignancy was detected in 40 out of 339 adult tonsillectomy specimens. Most of them had squamous cell carcinoma. In our study, two had malignancy. Of these two patients, one had mucoepidermoid carcinoma, (MEC) low grade type and the other had Squamous cell carcinoma. Histopathological finding of MEC suggestive of right Tonsil section studied shows normal tonsillar tissue with features of chronic tonsillitis. Also seen in a small focus of cells showing bimodal population of cells consisting of clear cells and epidermal cells showing glandular pattern with mild to moderate pleomorphism, Alcian blue: was positive for extracellular mucin.Post op patient was advised CT scan for neck node involvement. CT neck done was suggestive of nonspecific lymph nodes. Based on these findings the tumour was staged T1NOMO, hence the patient was further advised adjuvant radiotherapy. Patient had been following up for 6 months and at her last follow up she was symptom free.

Granulomatous inflammation is a chronic process that results from the activation of macrophages by antigens that are resistant to cellular digestion. It occurs in numerous settings including infection, most classically by Mycobacterium tuberculosis, but also fungi and unusual bacteria; neoplasia, commonly affected with Hodgkin's disease. ${ }^{14,15,16}$ Primary tonsillar tuberculosis is a rare entity, but still exists in regions of the world where the overall incidence of tuberculosis is high. ${ }^{17}$ Secondary spread to the oropharynx is a rare but described sequel of pulmonary disease.Diagnosis of tonsillar tuberculosis is made by histopathological findings and culture report ${ }^{18}$. The histopathological specimen from the patient initially failed to reveal acid fast bacilli. It was only after sections were stained with ZiehlNeelsen that a few isolated organism were identified. However, the patient was diagnosed soon after the tonsillectomy, treated appropriately, and experienced no long term sequelae. 


\section{Conclusion}

One of the biggest motivations for studies on whether tonsil specimen should be examined histopathologically is the fact that there is a debate on the cost and the loss of labor power. However, the results of the present study and many other studies suggest that histological examination should be performed routinely for every case of tonsillectomy in adult population and the risk factors should be considered in pediatric patients after tonsillectomy. In our study histopathological examination of the tonsils revealed diversity of pathological entities including Mucoepidermoid carcinoma, squamous cell carcinoma, granulomatous disease of tonsil and chronic inflammation with hyperplasia. This emphasizes the importance of histopathological examination of tonsils after tonsillectomy inspite of its normal appearance. With increasing incidence of tonsillar malignancy in the recent years, histopathological evaluation helps in early identification of underline pathology which could be missed clinically.

\section{References}

1. Dias EP, Rocha ML, Carvalho MOO, Amorim LMF. Detection of Epstein-Barr virus in recurrent tonsillitis. Braz $\mathrm{J}$ Otorhinolaryngol.2009;75(1):30-4.

2. Regauer S. Nasopharynx and Waldeyer's rings. In: Cardesa A, Slootweg PJ, editor. Pathology of the head and neck. New york: Springer; 2006,p. 183.

3. Scadding GK. Immunology of the tonsil: a review. J R Soc Med 1990;83:104-7.

4. Ying MD. Immunological basis of indications for tonsillectomy and adenoidectomy. Acta Otolaryngol Suppl (Stockh) 1988;454:279-85

5. Mattila PS, Tarkkanen J. Differentiation of $T$ lymphocytes in the human adenoid as measured by the expression of CD45 isoforms. Scand J Immunol 1998;48:59-64

6. Bergler W, Adam S, Gross HJ et al. Agedependent altered proportions in subpopulations of tonsillar lymphocytes. Clin Exp Immunol 1999;116:9-18

7. Karasalihoglu AR. Ear Nose Throat Diseases. Istanbul, Beta Press, 1988:125

8. Bizzell JG, Richter GT, Bower CM, Woods GL, Nolder AR. Routine pathologic examination of tonsillectomy specimens: A 10-year experience at a tertiary care children's hospital. Int J Pediatr Otorhinolaryngol 2017; 102: 86-9. [CrossRef]

9. Younis RT, Hesse SV, Anand VK. Evaluation of the utility and costeffectiveness of obtaining histopathologic diagnosis on all routine tonsillectomy specimens. Laryngoscope 2001; 111: 2166-9 [CrossRef]

10. Papouliakos S, Karkos PD, Korres G, Karatzias G, Sastry A, Riga M. Comparison of clinical and histopathological evaluation of tonsils in pediatric and adult patients. Eur Arch Otorhinolaryngol 2009; 266: 1309-13. [CrossRef]

11. Lopes O, Mimiça I, Godinho JC, Castro Jr NP, Bussoloti Filho I, Dolci JEL, et al. A lincomicina no tecido amigdaliano. Seus níveis séricos e tissulares. Correlações clínica, bacteriológica e histopatológica. Rev Bras Otorrinolaringol. 1982;48(2):339.

12. Ripplinger T, Theuerkauf T, SchultzCoulon HJ. Significance of the medical history in decisions on whether tonsillotomy is indicated. HNO 2007;55:945-9.

13. Strong EB, Rubinstein B, Senders CW. Pathologic analysis ofroutine tonsillectomy and adenoidectomy specimens. Otolaryngol Head Neck Surg 2001; 125 : 473-7. [CrossRef

14. Kadin M, Donaldson S, Dorfman R. Isolated granulomas in Hodgkin's disease. N Engl J Med 1970;283:859-861. 
15. O’Connell M, Schimpff S, Kirschner R, Abt A, Wiernik P. Epithelioid granulomas in Hodgkin disease. A favourable prognostic sign? JAMA 1975;233:886889.

16. Sacks E, Donaldson S, Gordon J, Dorfman R. Epithelioid granulomas associated with Hodgkin's disease: clinical correlations in 55 previously untreated patients. Cancer 1978; 41:562-567.

17. Anim J, Dawlatly E. Tuberculosis of the tonsil revisited. West Afr J Med 1991;10:194-197.

18. Selimoglu MD, Sutbeyaz Y, Ciftcioglu MA, Parlak M, Esrefoglu M, Ozturk A. Primary tonsillar tuberculosis: a case report. J Laryngol Otol 1995;109:880882. 